Report (1966), in which there was provision for direct reimbursement for ancillary help, other than doctors' wives.

In 1967 the Annual Representative Meeting passed the motions referred to above. M.M.S. was prepared to conduct a survey into this matter, since it held that its basic claim that doctors' expenses were assessed at an artificially low figure was unchanged by the abolition of the Pool. In the late summer of 1967 M.M.S. told Council that it proposed to offer its services to all general practitioners, and asked for B.M.A. support. At a special meeting in October the Council decided not to support M.M.S. at that time and to conduct the survey independently of the company. As that meeting was in camera the debate was not reported. It then became apparent that if the B.M.A. attempted to conduct the survey alone it would expose itself to legal action by M.M.S. for breach of confidentiality, and the six-hour debate at the last Council meeting served to make the dilemma plain.

This tangled situation should not be allowed to obscure the matter of real concern to ordinary general practitioners, nor would it be wise to let it drag on indefinitely. The survey, the M.M.S. scheme, and all the debates can be resolved into one question. Some doctors pay their wives notional salaries because there is no apparent advantage in paying them more. If these wives were paid at a higher rate would this lead in the end to a real financial benefit for general practitioners ? This is what the Representative Body will want to know.

\section{Vocational Aim}

At the heart of the clinical practice in which the great majority of doctors make their working life is the care of individual men and women. This gives a sense of value to their work and of purpose to their education. In their undergraduate years medical students are perhaps more fortunate than some of their contemporaries, for part of the dissatisfaction at present being expressed in universities is said to spring from a feeling of aimlessness. Certainly some faculties seem to produce graduates equipped for little else than to give a plausible reply in a sociological discussion on television. But is medical education clearly focused on producing the sort of doctors the patients need ?

A bone of contention for some time has been the amount and type of training that undergraduate students should receive to fit them for a career in general practice. Until recently men were living who began their medical career by apprenticeship to a general practitioner, ${ }^{1}$ an era ended by the General Medical Council in the nineteenth century. There followed a period up to the end of the second world war when undergraduate education became almost exclusively carried out by consultants in hospitals. The pendulum then swung back again, given a push in 1950 by the report of a B.M.A. committee $^{2}$ under Sir Henry Cohen, as he then was, and continued on its way under the impact of valuable individual studies and the advocacy of the Royal College of General Practitioners for a more realistic education. Consequently the recent report of the Royal Commission on Medical Education ${ }^{3}$ can write without fear of challenge, "We think that every undergraduate medical student should be given an insight

\footnotetext{
I See Cox, A., Brit. med. F., 1950, 1, 77.

2 General Practice and the Training of the General Practitioner. 1950. British Medical Association. London.

- Royal Commission on Medical Education 1965-68: Report. 1968. Cmnd. 3569 . H.M.S.O.

- Brit. med. F., 1968, 2, 65
}

into general practice." The educational experience proposed is not to train the student specifically for general practice but to show him how the problems that confront the family doctor are a part of medicine as a whole. In other words, real medicine does not begin and end at the hospital gates.

Graduating with a more complete idea of what medicine is about than their predecessors have often done, many of these young doctors could be expected to welcome vocational training for general practice. This was the subject of a conference held at the Royal College of General Practitioners on 5 June, on which a report appears at page 758 . Several schemes already in operation were discussed, but the need to get more of them past the planning stage was evident from the observation of Dr. J. Horder, chairman of the R.C.G.P.'s vocational training subcommittee, that at present only one in eight doctors are entering general practice through vocational training. No one doubted the need for it to be extended.

But questions remain to be answered, and indeed they attend the Royal Commission's report also. ${ }^{4}$ Have we the resources in men, money, buildings ? Men of initiative acting locally and with few facilities have already done much to encourage postgraduate and continuing education for doctors in practice. Practical enthusiasm is there, and many people would agree with Lord Platt, who told the conference that it is urgent to get on with vocational training without worrying too much about the relative responsibilities of different organizations or exactly where the money is to come from. But, short of making vocational training compulsory, many entrants to general practice are likely to fight shy of it when they can enter practice without it and earn two or three times as much. Thus like other desirable educational reforms the scheme will cost money, and not for the first time the nation will have to be made aware of the real costs of having a first-class medical service.

\section{The Postoperative Chest}

Postoperative chest complications have always been the bane of surgery, and they have been studied repeatedly by both surgeons and anaesthetists. Many reports on them have therefore accumulated, and the latest addition, by J. A. K. Wightman, ${ }^{1}$ may in time come to be regarded as a classic.

He studied 785 patients who had general surgical operations under general anaesthesia. The definition of what is a chest complication is clearly important, for the size of the fish caught will depend on the mesh of the net. Wightman takes a postoperative pulmonary complication to be present if there is a productive cough, a fever of $99^{\circ} \mathrm{F}$. $\left(37.2^{\circ} \mathrm{C}\right.$.) or over, with physical signs in the chest which were not present before. His sad but not unexpected conclusion is that the incidence of this complication has changed little during the past 30 years. He confirms once again that the site of operation is all-important, for though the total incidence of cases with chest complications after operation was $5 \%$ the abdominal cases accounted for $10 \%$ and the non-abdominal cases for only $0.6 \%$. Even among the abdominal cases the site of operation influenced the outcome, for the incidence rose steeply to $21 \%$ when the operation was on the gastroduodenal and biliary tract and was $18 \%$ for bladder and prostate operations, but was only $6 \%$ for other abdominal operations. In his careful analysis various other factors are brought out, and these tend on the whole to confirm what previous inves- 